Research Article

\title{
Screening of cetirizine for analgesic activity in mice
}

\author{
Priya $M^{*}$, Sathya Narayanan V, Satyajit Mohapatra, Jamuna Rani $\mathbf{R}$
}

Department of Pharmacology, S.R.M. Medical College Hospital $\&$ Research Centre, Chennai603203, Tamilnadu, India

Received: 21 December 2012 Accepted: 27 January 2013

\section{*Correspondence to:}

Dr. Priya M,

Email: drheartbeat@gmail.com

(C) 2013 Priya $\mathrm{M}$ et al. This is an open-access article distributed under the terms of the Creative Commons Attribution License, which permits unrestricted use, distribution, and reproduction in any medium, provided the original work is properly cited.

\begin{abstract}
Background: Pain is the most common symptom for which patients approach doctors. We have multitude of drugs for pain relief, but they have serious side effects ranging from peptic ulcer (e.g. NSAIDs) to renal failure. The other group, opioids have well known side effects ranging from sedation to drug dependence. So a search for a drug for analgesia with high therapeutic effect and fewer side effects will be a boon for the patients. The objective of this study was to find whether cetirizine, a second generation antihistaminic drug, has got any analgesic activity in mice.

Methods: Ten adult albino mice weighing 20-30 grams of either sex were randomized to two groups $(n=5)$. Group I: control group (Treated with solvent $0.1 \mathrm{ml} / \mathrm{kg}$ ), Group II: Test group (Cetirizine $1 \mathrm{mg} / \mathrm{kg}$ ). All drugs were given orally. The analgesic activity was evaluated by using tail flick, tail immersion and tail clip methods. Reaction time of animals to pain sensation before and after Cetirizine administration were noted at 0, 15, 30, 60 and 90 minutes time intervals respectively on Day $1,3,5,7,10$.

Results: Mean reaction time was expressed as Mean \pm SEM, and one way ANOVA was used to assess statistical significance. Cetirizine was found to have statistically significant analgesic effect in mice and time dependent increase in analgesic effect were observed in all three pain models and maximum analgesic activity was observed at 60 minutes $(p<0.001)$ after drug administration.

Conclusions: Through this study, Cetirizine, a second generation antihistamine, is found to have significant analgesic activity in mice. This effect has to be studied further elaborately in animals as well as in humans.
\end{abstract}

Keywords: Pain, Reaction time, Antihistamine, Cetirizine, Analgesic

\section{INTRODUCTION}

Analgesics are one of the commonest group of drugs prescribed by a physician for pain. One of the greatest services doctors can do to their patients is to acquire knowledge and skills in the management of pain. ${ }^{2}$ Pain can occur without tissue injury or evident disease and can persist after injury has healed. Under normal conditions, pain is associated with impulse activity in small-diameter (C and $\mathrm{A} \delta$ ) primary afferent fibres of peripheral nerves. ${ }^{1}$ These nerves have sensory endings in peripheral tissues and are activated by stimuli like mechanical, thermal and chemical. ${ }^{18}$ The majorities of umyelinated (C) fibres is associated with polymodal nociceptive endings and convey a dull, diffuse, burning pain, whereas myelinated (Aס) fibres convey a sensation of sharp, well-localized pain. $\mathrm{C}$ and $\mathrm{A} \delta$ fibres convey nociceptive information from muscle and viscera as well as from the skin. ${ }^{2}$ Nociception is a consequence of tissue injury (trauma, inflammation) causing the release of chemical mediators which activate nociceptors, defined as receptors that are capable of distinguishing between noxious and innocuous stimuli in the tissue. ${ }^{15}$

Studies indicate that it is also possible to increase sensitivity to noxious stimuli by activating histamine $\mathrm{H}$ receptors; mainly $\mathrm{H}_{1}$ receptor. ${ }^{6}$ It thus seems likely that the histaminergic system, like many other neuronal systems, plays an important role in the modulation of central perception of nociceptive stimuli. ${ }^{8}$

Analgesic drug: a drug that relieves pain due to multiple causes. Analgesics are classified as opioids (which act in the central nervous system, i.e. opioids) and NSAIDS 
(which act peripherally). The therapeutic efficacy of analgesics varies widely between individuals. They have a narrow therapeutic window and drug dosages may be limited to the onset of adverse reaction. ${ }^{2}$ Existing analgesics are prone to cause serious side effects like GI bleeding, ulceration \& renal toxicity. ${ }^{21}$ So a search of drug for analgesia with good therapeutic effect and fewer side effects will be a boon for the patients.

Cetirizine is a second generation antihistaminic drug, popularly used for rhinitis, urticaria and conjunctivitis. It has got selective $\mathrm{H} 1$ antihistaminic activity. It has desirable pharmacokinetic properties with high safety profile. ${ }^{14}$ In this study an attempt has been made to find whether Cetirizine, a second generation antihistaminic drug, has got any analgesic activity in mice.

\section{METHODS}

Materials: Cetirizine10 mg oral tablet were obtained from GlaxoSmithKline.

The Institutional Animal Ethical committee permitted the study.

Animals: Swiss albino mice (20-25 g) of either sex obtained from King Institute Chennai were used for the experiments. The animals were maintained in standard environmental conditions and housed in a light-controlled room at a temperature of $24^{\circ} \mathrm{C}$ and a humidity of $60 \pm$ $10 \%$ fed on a standard diet with water ad libitum.

Experimental protocol: The mice were randomly divided into 2 groups $(\mathrm{n}=5)$ as follows:

Group 1: Control (treated with distilled water $0.1 \mathrm{ml} / \mathrm{kg}$ ) Group 2: Test (treated with Cetirizine $1 \mathrm{mg} / \mathrm{kg}$ )

The Analgesic effects were examined through tail flick, tail clip and tail immersion tests. ${ }^{4,5}$ Drugs were given once daily orally for 10 days to observe for chronic effect. Distilled water was used as a solvent for cetirizine. Reaction time of animals before and after drug will be noted at an interval of $0,15,30,60$ and 90 minutes on day 1,3,5,7 and 10 for both acute and chronic effect.

Tail flick response: This method is used to induce thermal pain stimuli. The tail of each mouse was placed on the nichrome wire of an analgesiometer, which was fixed at $5.5 \pm 0.5 \mathrm{amp}$. The time taken by the animal to withdraw (flick) its tail from the hot wire was taken as the reaction time. Cut off time is kept as 12 seconds. ${ }^{5}$ Reaction time of animals before and after drug will be noted at an interval of $0,15,30,60$ and 90 minutes.

Tail clip method: All the mice were screened by applying a metal artery clip to the base of the tail with its jaw sheathed with thin rubber tubing. The pressure exerted by the clip was so adjusted that it was just sufficient to make all control mice respond.
This method was used to induce mechanical pain stimuli. A tail clip was applied and a positive analgesic response was indicated if there was no attempt to dislodge the clip within10 sec. Cut off time is kept as 10 seconds. Reaction time of animals before and after drug will be noted at an interval of $0,15,30,60$ and 90 minutes.

Tail immersion method: The tail (up to $5 \mathrm{~cm}$ ) was then dipped in a beaker of water maintained at $55 \pm 0.5^{\circ} \mathrm{C}$. The time in seconds to withdraw the tail clearly out of the water was taken as the reaction time. Cut off time is kept as 15 seconds. Reaction time of animals before and after drug will be noted at an interval of $0,15,30,60$ and 90 minutes.

Statistical analysis: Reaction times subjected to analysis using Microsoft excel software: mean \pm s.e.m. Significance given by $\mathrm{p}$ value $<0.05$. Multiple comparison was performed using one way ANOVA test followed by Tukey's multiple comparison tests was applied for the statistical analysis of the data in order to facilitate the comparisons of within group as well as inter-group differences.

\section{RESULTS}

Cetirizine administered at a dose of $1 \mathrm{mg} / \mathrm{kg}$ showed statistically significant analgesic activity in mice in all three tests used. Maximum possible analgesia was observed at 60 minutes after drug administration in all three tests.

\section{Analgesic activity of cetirizine by tail-flick method}

The mean reaction time of the cetirizine treated group after 15 and 30 minutes of drug administration was $5.6 \pm 0.57$ and $8.4 \pm 0.59$ seconds respectively (Table 1) It had statistically significant analgesic activity $(p<0.001)$ in comparison with control group. The maximum possible analgesia was observed at 60 minutes after drug administration $10.4 \pm 0.57 \mathrm{sec}$ (Figure 1) which is highly significant $(p<0.001)$.

\section{Analgesic activity of cetirizine by tail clip method}

The mean reaction time of the cetirizine treated group after 15 and 30 minutes of drug administration was $3.04 \pm 0.32$ and $7.88 \pm 0.91$ seconds respectively (Table 2 ). It had statistically significant analgesic activity $(p<0.001)$ in comparison with control group. Here also the maximum possible analgesia was observed at 60 minutes after drug administration 10 seconds which is highly significant $(p<0.001)$ in comparison with the control (Figure 2).

\section{Analgesic activity of cetirizine by tail immersion method}

The mean reaction time of the cetirizine treated group after 15 and 30 minutes of drug administration was $2.92 \pm 0.27$ and $7.76 \pm 0.55$ seconds respectively (Table 3 ). 
This also showed statistically significant analgesic activity $(p<0.001)$ in comparison with control group. Here also the maximum possible analgesia was observed at 60 minutes $(11.7 \pm 0.48$ seconds $)$ after drug administration which is highly significant $(p<0.001)$ in comparison with the control (Figure 3).

Table 1: Analgesic activity of Cetirizine by Tail flick method.

\begin{tabular}{|c|c|c|c|c|c|c|}
\hline \multirow{2}{*}{ Day } & \multirow{2}{*}{ Group } & \multicolumn{5}{|c|}{ Reaction time in seconds } \\
\hline & & $0 \mathrm{~min}$ & $15 \mathrm{~min}$ & $30 \mathrm{~min}$ & $60 \mathrm{~min}$ & $90 \mathrm{~min}$ \\
\hline \multirow[b]{2}{*}{1} & Control (DW) & $0.7 \pm 0.18$ & $0.84 \pm 0.23$ & $1.14 \pm 0.10$ & $1.02 \pm 0.17$ & $0.90 \pm 0.2$ \\
\hline & Cetirizine & $1.26 \pm 0.11$ & $5.6 \pm 0.57^{*}$ & $8.4 \pm 0.59^{*}$ & $10.4 \pm 0.57^{*}$ & $3.7 \pm 0.23^{*}$ \\
\hline \multirow[b]{2}{*}{3} & Control(DW) & $0.88 \pm 0.22$ & $0.56 \pm 0.13$ & $0.46 \pm 0.04$ & $0.82 \pm 0.14$ & $0.7 \pm 0.13$ \\
\hline & Cetirizine & $1.22 \pm 0.28$ & $5.32 \pm 0.65^{*}$ & $7.86 \pm 0.44^{*}$ & $10.8 \pm 0.41^{*}$ & $3.84 \pm 0.16^{*}$ \\
\hline \multirow{2}{*}{5} & Control(DW) & $0.79 \pm 0.12$ & $0.8 \pm 0.13$ & $0.6 \pm 0.11$ & $0.76 \pm 0.16$ & $1.2 \pm 0.13$ \\
\hline & Cetirizine & $0.94 \pm 0.17$ & $6.4 \pm 0.59^{*}$ & $8.74 \pm 0.55^{*}$ & $10.8 \pm 0.28^{*}$ & $4.82 \pm 0.36^{*}$ \\
\hline \multirow{2}{*}{7} & Control(DW) & $1.34 \pm 0.21$ & $1.24 \pm 0.21$ & $1.22 \pm 0.28$ & $1.08 \pm 0.18$ & $1.22 \pm 0.28$ \\
\hline & Cetirizine & $0.89 \pm 0.17$ & $5.94 \pm 0.43^{*}$ & $8.74 \pm 0.55^{*}$ & $11.56 \pm 0.31^{*}$ & $4.36 \pm 0.2^{*}$ \\
\hline \multirow{2}{*}{10} & Control(DW) & $1.12 \pm 0.06$ & $1.32 \pm 0.12$ & $1.14 \pm 0.1$ & $1.54 \pm 0.22$ & $1.38 \pm 0.13$ \\
\hline & Cetirizine & $0.92 \pm 0.14$ & $6.1 \pm 0.71^{*}$ & $10.6 \pm 0.83^{*}$ & $12 \pm 0.0^{*}$ & $5.18 \pm 0.28^{*}$ \\
\hline
\end{tabular}

${ }^{*} p<0.001$ compared to control group. Values are mean \pm SEM $(n=5)$.

Table 2: Analgesic activity of Cetirizine by Tail clip method.

\begin{tabular}{|c|c|c|c|c|c|c|}
\hline \multirow{2}{*}{ Day } & \multirow{2}{*}{ Group } & \multicolumn{5}{|c|}{ Reaction time in seconds } \\
\hline & & $0 \mathrm{~min}$ & $15 \mathrm{~min}$ & $30 \mathrm{~min}$ & $60 \mathrm{~min}$ & $90 \mathrm{~min}$ \\
\hline \multirow[b]{2}{*}{1} & Control (DW) & $1.16 \pm 0.1$ & $0.84 \pm 0.17$ & $0.89 \pm 0.17$ & $0.89 \pm 0.16$ & $0.60 \pm 0.11$ \\
\hline & Cetirizine & $1.01 \pm 0.14$ & $3.04 \pm 0.32^{*}$ & $7.88 \pm 0.91^{*}$ & $8.62 \pm 0.99^{*}$ & $4.22 \pm 0.38^{*}$ \\
\hline \multirow{2}{*}{3} & Control(DW) & $1.06 \pm 0.18$ & $1.14 \pm 0.2$ & $1.18 \pm 0.2$ & $1.48 \pm 0.16$ & $1.3 \pm 0.21$ \\
\hline & Cetirizine & $1.03 \pm 0.19$ & $5.5 \pm 0.5^{*}$ & $8.8 \pm 0.65^{*}$ & $9.8 \pm 0.22^{*}$ & $3.96 \pm 0.28^{*}$ \\
\hline \multirow{2}{*}{5} & Control(DW) & $1.12 \pm 0.06$ & $1.24 \pm 0.12$ & $1.34 \pm 0.21$ & $1.16 \pm 0.1$ & $1.34 \pm 0.07$ \\
\hline & Cetirizine & $1.14 \pm 0.2$ & $6.92 \pm 0.77^{*}$ & $8.8 \pm 0.89^{*}$ & $9.3 \pm 0.78^{*}$ & $3.9 \pm 0.37^{*}$ \\
\hline \multirow{2}{*}{7} & Control(DW) & $0.89 \pm 0.16$ & $0.8 \pm 0.18$ & $0.9 \pm 0.12$ & $0.82 \pm 0.14$ & $0.76 \pm 0.18$ \\
\hline & Cetirizine & $1.2 \pm 0.10$ & $6.36 \pm 0.88^{*}$ & $9.46 \pm 0.40^{*}$ & $10^{*}$ & $3.62 \pm 0.22^{*}$ \\
\hline \multirow{2}{*}{10} & Control(DW) & $0.82 \pm 0.21$ & $0.6 \pm 0.16$ & $0.83 \pm 0.13$ & $0.96 \pm 0.13$ & $0.9 \pm 0.19$ \\
\hline & Cetirizine & $1.24 \pm 0.12$ & $6.08 \pm 0.47^{*}$ & $9.46 \pm 0.4^{*}$ & $10^{*}$ & $4.14 \pm 0.14^{*}$ \\
\hline
\end{tabular}

${ }^{*} p<0.001$ compared to control group. Values are mean $\pm \operatorname{SEM}(n=5)$.

In vivo antinociceptive activity in mice: Cetirizine given by oral route in mice showed a significant and timedependent increase in analgesic activity in all the three tests used (Table 1, Table 2 and Table 3 ).
From these results it is clear that Cetirizine possesses central analgesic activity and chronic study (Figure 4) showed statistically significant increase in analgesic activity on day 10 when compared with day 1 at 15,30,60 and 90 minutes after drug administration $(p<0.001)$. 


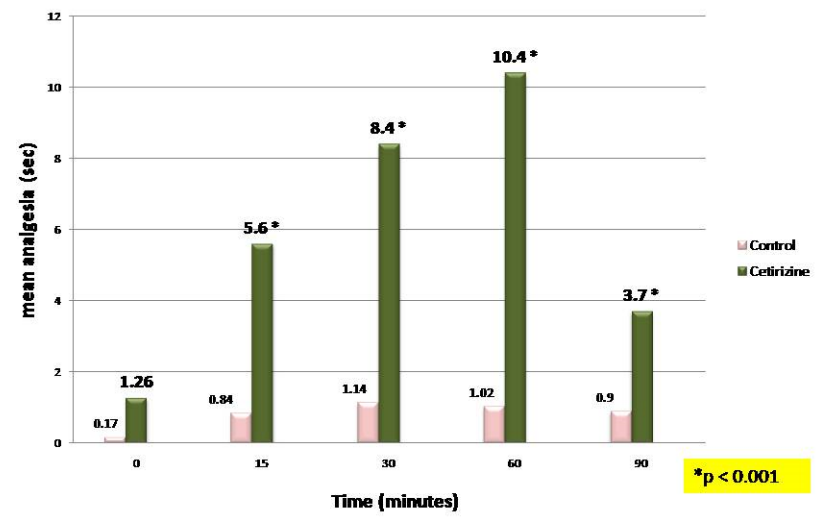

Figure 1: Maximum possible analgesic effect of cetirizine on day-1 by tail flick method.

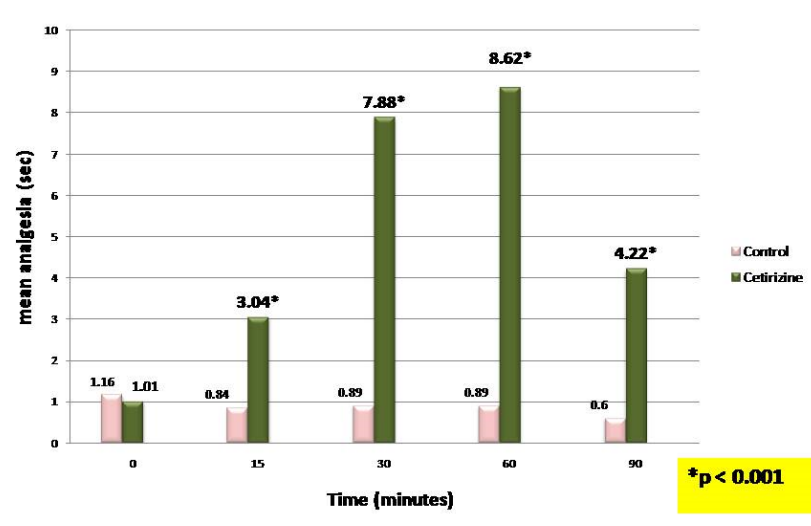

Figure 2: Analgesic effect of cetirizine on day-1 by tail clip method.

Table 3: Analgesic activity of Cetirizine by Tail immersion technique.

\begin{tabular}{|cllllll|}
\hline \multirow{2}{*}{ Day } & Group & \multicolumn{5}{c|}{ Reaction time in seconds } \\
\cline { 3 - 7 } & & $0 \mathrm{~min}$ & $15 \mathrm{~min}$ & $30 \mathrm{~min}$ & $60 \mathrm{~min}$ & $90 \mathrm{~min}$ \\
\hline \multirow{3}{*}{1} & Control (DW) & $1.12 \pm 0.06$ & $1.3 \pm 0.13$ & $1.64 \pm 0.24$ & $1.54 \pm 0.22$ & $1.36 \pm 0.1$ \\
\cline { 2 - 7 } & Cetirizine & $0.66 \pm 0.10$ & $2.92 \pm 0.27$ & $7.76 \pm 0.55^{*}$ & $11.7 \pm 0.48^{*}$ & $3.92 \pm 0.30^{*}$ \\
\hline \multirow{2}{*}{3} & Control(DW) & $0.82 \pm 0.14$ & $0.9 \pm 0.11$ & $1.1 \pm 0.32$ & $0.94 \pm 0.21$ & $1.1 \pm 0.20$ \\
\hline \multirow{2}{*}{5} & Cetirizine & $0.91 \pm 0.21$ & $3.07 \pm 0.24^{*}$ & $7.66 \pm 0.43^{*}$ & $11.5 \pm 0.21^{*}$ & $3.88 \pm 0.2^{*}$ \\
\hline \multirow{2}{*}{7} & Control(DW) & $1 \pm 0.17$ & $1.14 \pm 0.27$ & $1.14 \pm 0.27$ & $1.3 \pm 0.26$ & $1.1 \pm 0.2$ \\
\hline \multirow{2}{*}{10} & Cetirizine & $0.94 \pm 0.13$ & $6.94 \pm 0.72^{*}$ & $9.51 \pm 0.34^{*}$ & $12.5 \pm 0.3^{*}$ & $5.06 \pm 0.52^{*}$ \\
\hline & Control(DW) & $0.81 \pm 0.12$ & $0.7 \pm 0.13$ & $0.8 \pm 0.14$ & $0.66 \pm 0.1$ & $1.66 \pm 0.16$ \\
\hline & Cetirizine & $1.06 \pm 0.18$ & $6.45 \pm 0.35^{*}$ & $10.14 \pm 0.45^{*}$ & $13.12 \pm 0.54^{*}$ & $4.9 \pm 0.45^{*}$ \\
\hline & Control(DW) & $0.7 \pm 0.1$ & $0.7 \pm 0.13$ & $0.98 \pm 0.26$ & $0.8 \pm 0.22$ & $1.02 \pm 0.15$ \\
\hline
\end{tabular}

${ }^{*} p<0.001$ compared to control group. Values are mean $\pm \operatorname{SEM}(n=5)$

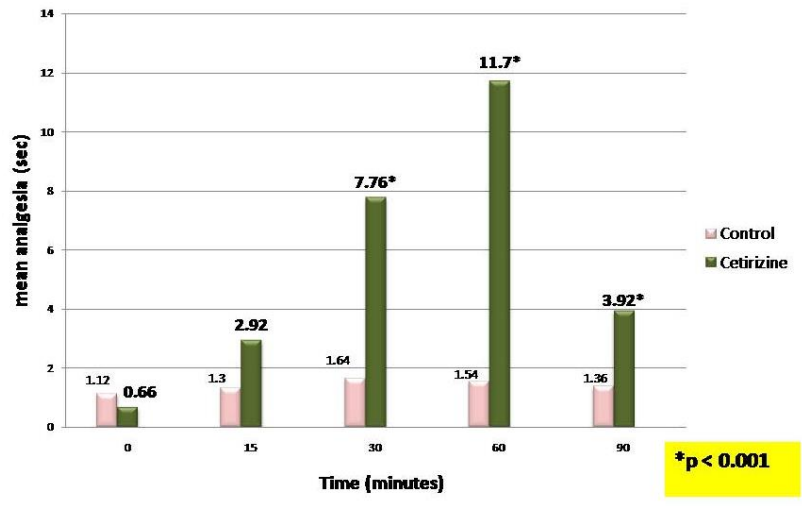

Figure 3: Maximum possible analgesia of cetirizine on day-1 by tail immersion technique.

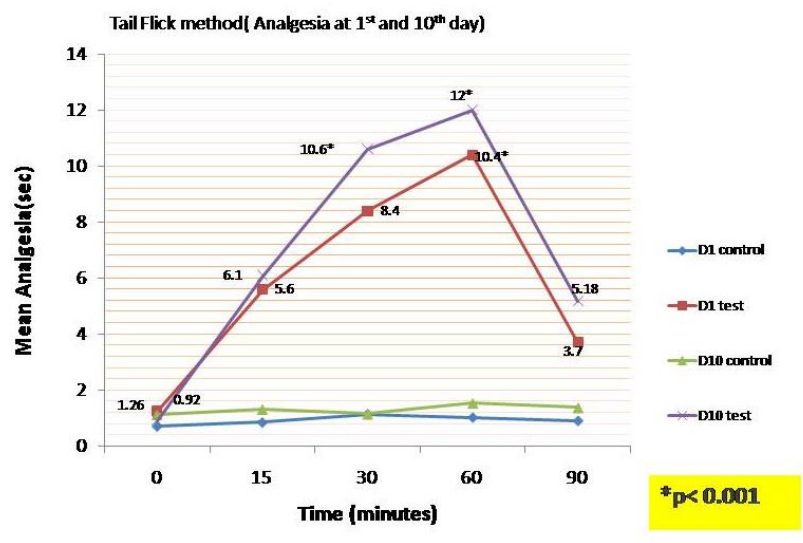

Figure 4: Chronic analgesic effect of cetirizine. 


\section{DISCUSSION}

In the present study, cetirizine was investigated for analgesic activity in mice. Cetirizine administered at a dose of $1 \mathrm{mg} / \mathrm{kg}$ showed statistically significant analgesic activity in mice and maximum possible analgesia was observed at one hour after drug administration.

Histamine is also released from local cells and directly excites nociceptors. ${ }^{3}$ Several studies have demonstrated that histamine $\mathrm{H}_{1}$ receptors play some role in physiological and pathological pain perception. The histaminergic neuron system arises from the tuberomammillary nucleus of the posterior hypothalamus receiving input mainly from the limbic system and projects efferent nerve fibers to almost all parts of the brain. ${ }^{8}$ Studies suggests that histamine could modulate nociception at the cutaneous tissue level, the dorsal horn in the spinal cord and supraspinal including dorsal raphe nucleus in the medulla and periaqueductal gray in the midbrain through Histamine $\mathrm{H}_{1}$ receptors. ${ }^{6,8}$

Central facilitation is an important component of pathological hyperalgesia (e.g. that associated with inflammatory responses). The mediators responsible for central facilitation include substance P, CGRP, nerve growth factor (NGF), brain-derived neurotrophic factor (BDNF) and NO as well as many others. ${ }^{15,20}$

Histamine enhances nerve growth factor secretion in pain and inflammation. ${ }^{10,11,13}$ Nerve growth factor (NGF) is a member of family of peptides known as neurotrophins. Recently, studies have shown that nerve growth factor (NGF) is a major mediator of inflammatory and neuropathic pain, providing a new therapeutic target. Although originally discovered as a tropic factor for sympathetic and sensory neurons during development, it now appears that in adults, levels of NGF are elevated in many acute and chronic pain conditions. ${ }^{19}$ Furthermore, preclinical animal models of inflammatory and neuropathic pain also show increased NGF levels ${ }^{12}$, while the sequestration of NGF alleviates the associated hyperalgesia. The molecular mechanisms involved are being elucidated. ${ }^{9}$ Involvement of NGF in hyperalgesia has also been shown in human studies carried out as part of the first phase of clinical trials to assess the safety of NGF. ${ }^{17}$ The patients reported muscle ache in response to systemically administered NGF. Subcutaneous injections resulted in local tenderness to touch and heat. ${ }^{16}$

In our study, in addition to acute analgesic effect, chronic effect of the drug was also observed, which provides a support for the use of cetirizine as an analgesic clinically for both acute and chronic pain.

\section{CONCLUSION}

Cetirizine, a selective $\mathrm{H}_{1}$ antihistaminic drug is found to have significant analgesic activity in mice ( $1 \mathrm{mg} / \mathrm{kg}$ dose $)$. This effect might be due to blockade of $\mathrm{H}_{1}$ histaminergic receptor, which mediates pain directly or indirectly by decreasing Nerve Growth Factor peptide level, as histamine has an influence on the secretion of Nerve Growth Factor peptide, which is responsible for hyperalgesia. This effect has to be studied further elaborately. Comparison of Cetirizine's analgesic activity with the standard is in progress in our next study. Further research would be of interest to explain the exact mechanism of this analgesic effect.

\section{ACKNOWLEDGEMENTS}

The authors are thankful to Dr. James Pandian, Dean, S.R.M Medical College Hospital \& Research Centre for continuing support.

Funding: Department of Pharmacology, S.R.M. Medical College

Competing interests: None declared

Ethical approval: Obtained from Institutional Animal Ethical committee

\section{REFERENCES}

1. Merskey H, Bogduk N. Classifications of chronic pain: Description of chronic pain syndromes and definition of pain terms. Report by the International Association for the Study of Pain Task Force on Taxonomy. In: Merskey H, Bogduk N, editors. Seattle: IASP Press; 1994:209-14.

2. Bennett PN, Brown MJ. Nervous System: Pain and analgesics. In: Clinical Pharmacology. 10th ed. Edinburgh, Scotland: Churchill Livingstone; 2008:293-6.

3. Kumar V, Abbas AK, Fausto N. Histamine as mediator of pain and inflammation. In: Robbins and Cotran Pathologic Basis of Disease, edited by Kumar V, Abbas AK, Fausto N, editors. Philadelphia, PA: Elsevier Saunders, 2010:48-85.

4. Ghosh MN. Evaluation techniques for analgesic activity. In: Fundamental of Experimental Pharmacology. Calcutta India: Scientific Book Agency; 3rd ed., 2007:175-9.

5. Gerhard Vogel H, Chapter H. Central analgesic activity. In: Vogel Drug discovery and evaluation, 2nd edition, Springer-Verlag: Berlin, New York, I2002:692-8.

6. Mobarakeh JI, Sakurada S, Katsuyama S, Kutsuwa M, Kuramasu A, Lin ZY, et al. Role of histamine $\mathrm{H}(1)$ receptor in pain perception: a study of the receptor gene knockout mice. Eur J Pharmacol 2000;391:81-9.

7. Malmberg-Aiello P, Lamberti C, Ghelardini C, Giotti A, Bartolini A. Role of histamine in rodent antinociception. Br J Pharmacol 1994;111:1269-79.

8. Malmberg-Aiello P, Lamberti C, Ipponi A, Bartolini A, Schunack W. Evidence for hypernociception induction following histamine $\mathrm{H} 1$ receptor activation in rodents. Life Sci 1998;63:463-76. 
9. Watson JJ, Allen SJ, Dawbarn D. Targeting nerve growth factor in pain: what is the therapeutic potential? BioDrugs 2008;22:349-59.

10. Kanda N, Watanabe S. Histamine enhances the production of nerve growth factor in human keratinocytes. J Invest Dermatol 2003;121:570-7.

11. Lipnik-Stanglj M, Carman-Krzan M. The effects of histamine and interleukin-6 on NGF release from cortical astrocytes in primary culture. Pflugers Arch 2000;440(5 Suppl):R99-100.

12. Lipnik-Stangelj M, Carman-Krzan M. Histaminestimulated nerve growth factor secretion from cultured astrocyctes is blocked by protein kinase C inhibitors. Inflamm Res 2004;53 Suppl 1:S57-8.

13. Stempelj M, Ferjan I. Signaling pathway in nerve growth factor induced histamine release from rat mast cells. Inflamm Res 2005;54:344-9.

14. Babe KS, Serafin WE. Histamine, bradykinin, and their antagonists. In: Brunton LL, Chabner BA, Knollmann BC, editors. Goodman \& Gilman's The Pharmacological Basis of Therapeutics. 12th ed. New York: McGraw-Hill; 2011:920-6.

15. Rang HP, Dale MM, Ritter JM, Flower RJ, Henderson G. Neural mechanism of pain. In: Rang and Dale's Pharmacology. 7th edn. Edinburgh: Elsevier; 2012:505-6.

16. Rueff A, Mendell LM. Nerve Growth Factor and Inflammatory Pain. Technical Corner from IASP
Newsletter, January/February 1996. Available at http://www.iasppain.org/AM/Template.cfm?Section=Technical_Cor ner\&Template $=/ \mathrm{CM} /$ ContentDisplay.cfm\&ContentI $\mathrm{D}=2204$.

17. Petty BG, Cornblath DR, Adornato BT, Chaudhry $\mathrm{V}$, Flexner C, Wachsman $\mathrm{M}$, et al. The effect of systemically administered recombinant human nerve growth factor in healthy human subjects. Ann Neurol 1994;36:244-6.

18. Julius D, Basbaum AI. Molecular mechanisms of nociception. Nature 2001;413:2013-10.

19. Lewin GR, Mendell LM. Nerve growth factor and nociception. Trends Neurosci 1993;16:353-9.

20. Ji RR, Kohno T, Moore KA, Woolf CJ. Central sensitization and LTP: do pain and memory share similar mechanisms? Trends Neurosci 2003;26:696705.

21. Furst DE, Ulrich RW, Varkey-Altamirano C. Nonsteroidal anti-inflammatory drugs, disease modifying antirheumatic drugs, nonopiod analgesics \& drugs used in gout. In: Katzung BG, Masters SB, Trevor AJ, editors. Basic and Clinical Pharmacology. 11th edition. New York, NY, USA: McGraw Hill; 2009:624.

doi:10.5455/2319-2003.ijbcp20130313

Cite this article as: Priya M, Sathya NV, Mohapatra $\mathrm{S}$, Jamuna RR. Screening of cetirizine for analgesic activity in mice. Int $\mathrm{J}$ Basic Clin Pharmacol 2013;2:187-92. 